$$
\text { CONF- } 9310291--1
$$

\title{
Interlaminar Strains at the Free Edge of a Hole in Laminated Composites: An Experimental Study
}

\author{
Raymond G. Boeman \\ Engineering Technology Division \\ Oak Ridge National Laboratory*
}

Prepared for the proceedings of the Eighth Technical Conference on Composite Materials

October 19-21, 1993

Cleveland, Ohio

\begin{abstract}
"The submitted manuscript has been authored by a contractor of the U.S.

Government under contract No. DE-AC05-

$840 R 21400$. Accordingly, the U.S.

Government retains a nonexclusive,

royalty-free licence to publish or reproduce

the published form of this contribution, or allow others to do so, for U.S. Govemment purposes."
\end{abstract}

*Oak Ridge National Laboratory is managed by Martin Marietta Energy Systems, Inc., for the U.S. Department of Energy under contract DE-AC05-84OR21400. 


\section{DISCLAIMER}

This report was prepared as an account of work sponsored by an agency of the United States Government. Neither the United States Government nor any agency thereof, nor any of their employees, makes any wartanty, express or implied, or assumes any legal liability or responsibility for the accuracy, completeness, or usefulness of any information, apparatus, product, or process disclosed, or represents that its use would not infringe privately owned rights. Reference herein to any specific commercial product, process, or service by trade name, trademark, manufacturer, or otherwise does not necessarily constitute or imply its endorsement, recommendation, or favoring by the United States Government or any agency thereof. The views and opinions of authors expressed herein do not necessarily state or reflect those of the United States Government or any agency thereof. 


\title{
Interlaminar Strains at the Free Edge of a Hole in Laminated Composites: An Experimental Study
}

\author{
RAYMOND G. BOEMAN
}

\begin{abstract}
Free-edge effects in laminated composite materials were studied experimentally using high-sensitivity moiré interferomety. Six laminates from two material systems were tested in uniaxial compression on an electro-mechanical testing machine. Interlaminar deformations were measured on a ply-by-ply basis at the straight free-edge and, for the first time, on the cylindrical surface of a hole. Strain distributions were determined with high fidelity for the hole surface and the straight free edge of the thick composite panels. Comparisons were made on a ply-by-ply basis for the transverse and tangential strains at the horizontal centerline of the hole ( $90^{\circ}$ location) and the corresponding plies at the straight boundaries.
\end{abstract}

\section{INTRODUCTION}

The free-edge problem has attracted considerable attention during the past two decades. The proliferation of analytical investigations is a direct result of experimental observations indicating that laminate strength and failure modes can be influenced significantly by the stacking sequence of the individual layers. Adjacent layers with differing fiber orientations exhibit a mismatch in free-ply deformations when loaded either mechanically or thermally. Continuity of displacements at the interfaces gives rise to interlaminar stresses at the free-edge. These stresses exist in a boundary layer region and are not accounted for by classical lamination theory (CLT). Singular behavior is exhibited by some of these stresses making laminates susceptible to delamination at the free-edge. Delamination is especially deleterious for thick composites loaded in compression possibly leading to catastrophic failure due to loss of structural stability. A fundamental understanding of the interlaminar stress field associated with the free-edge in laminated composites is critical in order to develop delamination prediction models as one criteria in assessing the design of structural components. Consequently, many different analytical-numerical approaches have been undertaken to analyze this problem. For straight free edges, these include finite-difference and finite-element techniques, boundary layer approaches, force balance methods, stress potentials, substructuring, and others. Even for the relatively simplistic case of the straight free edge, discrepancies exist between different solutions even to the extent of the sign of the local stress field as shown in Figure 1 [1-4].

Requirements for cut-outs or access holes in composite laminates necessitate the determination of the interlaminar response at the curved free edge of a hole. The presence of a hole complicates the problem enormously. Unlike the straight free edge problem where the response is independent of the axial coordinate, this problem is inherently three-dimensional.

Composite Materials and Structures Section, Engineering Technology Division, Oak Ridge National Laboratory, P.O. Box 2003, Oak Ridge, Tennessee, 37831-7294. Oak Ridge National Laboratory is managed by Martin Marietta Energy Systems, Inc., for the U.S. Department of Energy under contract DE-AC05-84OR21400. 


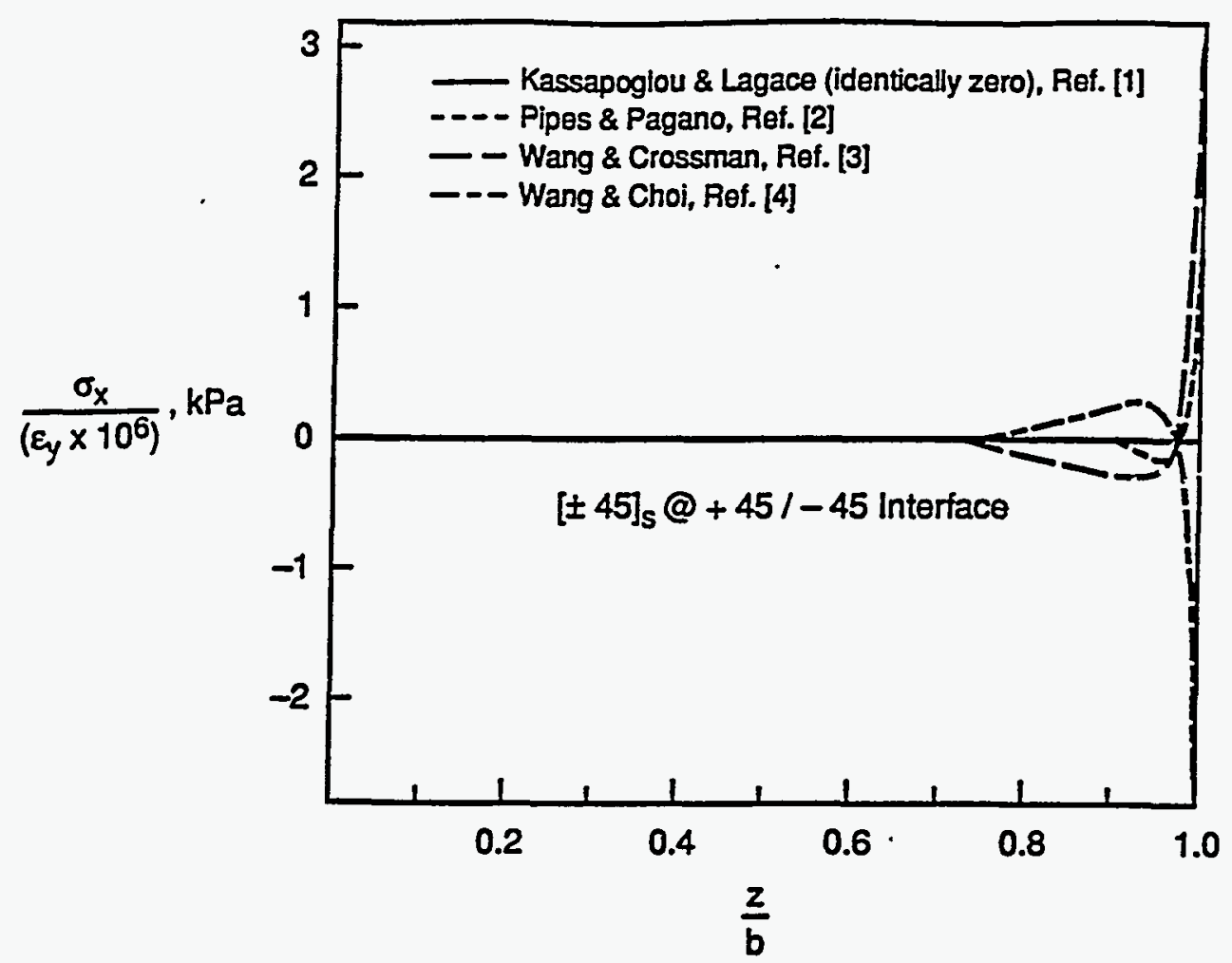

Figure 1 Comparison of different analyses for the interlaminar normal stress distribution $\sigma_{x}$ along $a+45 /-45$ interface for $a[ \pm 45]$ s laminate. The distance $z$ is normalized by the half-width b. (After Kassapoglou and Lagace, Ref. [1])

Three-dimensionality increases the computational burden dramatically to the point of becoming practically intractable. In fact, many authors investigating the straight free edge problem sought approaches to reduce the computational burden of their two dimensional analyses. Accordingly, much interest has shifted to approximate solutions to permit the study of "realworld" laminates. For the curved free edge, the analytical approaches taken include the finiteelement method, boundary layer approaches, force balance techniques, stress potentials and others.

The myriad of analytical-numerical approaches and their seemingly conflicting results suggests a clear need for experimental data to which the analytical solutions can be compared and validated. Experimental investigations however, as reported in the literature, are far less abundant than analytical investigations. Moreover, measurements are generally taken in the gross sense. That is, the desired quantities are either measured on the face of the laminate, or the gage-length of the measurement technique is too large (as in the case of strain gages) to measure ply-by-ply variations. Experimental approaches to obtain the global response have included moiré, photo-elastic coatings and strain gage techniques.

Reported herein are partial results of an extensive experimental program that utalized high-sensitivity moiré interferometry $[5,6]$ to study free-edge effects along the cylindrical surface of a hole in thick composite laminates. The goal was to generate unique data that reveals the ply-by-ply distributions of the interlaminar strains on the cylindrical surface of the hole. The data are intended to document the phenomenological behavior and serve as a benchmark to which analytical and numerical studies can be compared and verified. 


\section{SPECIMENS AND. TEST PROCEDURES}

Six composite laminates, $254 \mathrm{~mm}$ (10 in.) long by $127 \mathrm{~mm}$ ( 5 in.) wide, were machined from panels fabricated from two different material systems. Specimen designations, thicknesses, material types, and stacking sequences are given in Figure 2. All specimens except B1 and B2 contained centrally located holes. A convenient hole size of $25.4 \mathrm{~mm}$ (1 in.) was chosen to facilitate the experimental investigations on the surface of the hole. Specimens $\mathrm{B} 1, \mathrm{~B} 1 \mathrm{H}, \mathrm{B} 2$, and B2H were fabricated from Toray T800H/3900-2 graphite-epoxy which incorporates toughened-compliant interleaves between layers to improve the damage tolerance.

Coordinate axis $x, y, \theta$, as shown in Figure 2, were chosen such that $y$ is in the direction of loading, $x$ is the though thickness direction, and $\theta$ is measured with respect to $y$. The displacements in the $x$ and $y$ directions are given by $U_{x}$ and $U_{y}$ respectively. This coordinate system was chosen to be consistent with the usual convention used for optical measurements. That is, $U_{x}$ and $U_{\theta}$ denote the in-plane displacements (in this case the surface of the free edge.)
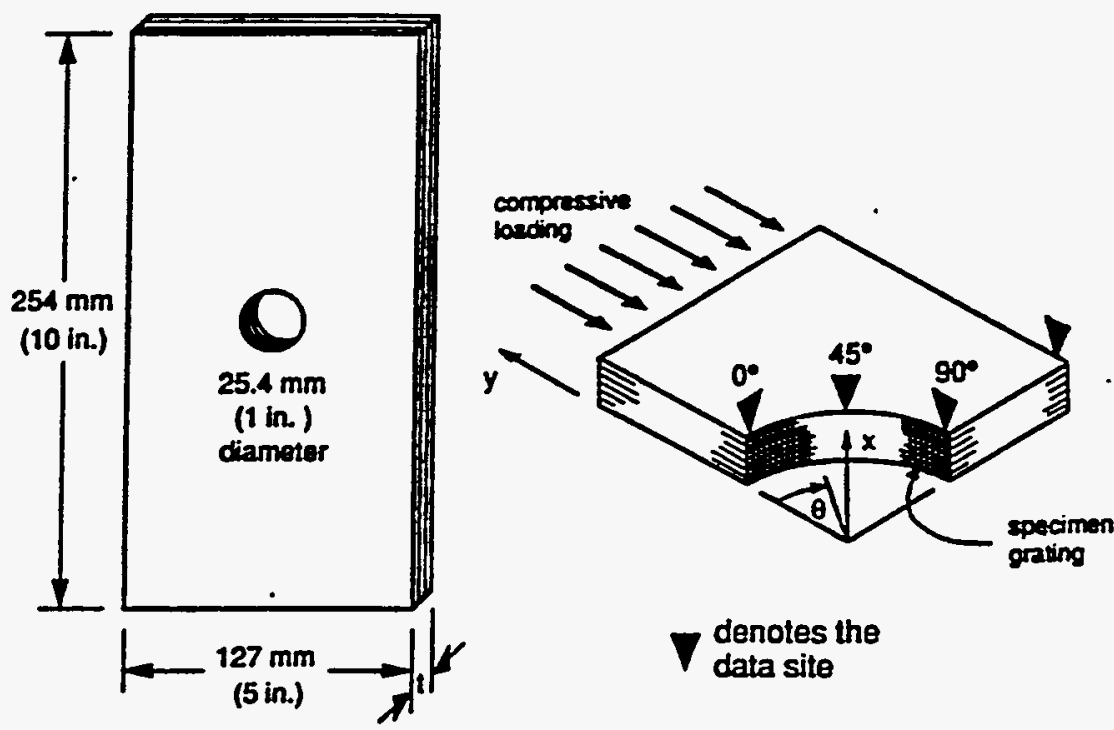

\begin{tabular}{|c|c|c|c|}
\hline Specimen & Material & Slacking Sequence & $\mathrm{t}, \mathrm{mm}$ \\
\hline B1, B1H & $\begin{array}{l}\text { T800H } \\
3900-2\end{array}$ & $\begin{array}{c}{\left[45_{2} / 45_{2} / \mathrm{O}_{2} / 90 / \pm 45_{2} /\right.} \\
\left.45_{2} /-45_{2} / \mathrm{O}_{2} / 90\right]_{8}\end{array}$ & $7.11 \mathrm{~mm}$ \\
\hline $\mathrm{B2}, \mathrm{B2H}$ & $\begin{array}{l}\text { T800H } \\
3900-2\end{array}$ & $\begin{array}{l}{\left[45 / 90 /-45 / 0_{3} / 45 / 0_{4} /\right.} \\
\left.-45 / 0_{2} / 45 / 0 /-45 / 90\right]_{8}\end{array}$ & $7.11 \mathrm{~mm}$ \\
\hline N1 & $\begin{array}{l}\text { AS4I } \\
3502\end{array}$ & {$\left[90_{3} / 45_{3} / 0_{3} /-45_{3}\right]_{2}$} & $6.73 \mathrm{~mm}$ \\
\hline N2 & $\begin{array}{l}\text { AS41 } \\
3502\end{array}$ & {$\left[9 \mathrm{O}_{2} / \mathrm{O}_{4}\right]_{4 s}$} & $6.73 \mathrm{~mm}$ \\
\hline
\end{tabular}

Figure 2 Specimen geometry, designation, material, and stacking sequence. 
Prior to testing, each end of the specimen was clamped into end-fixtures for better load transfer. The specimen, in the end-fixture, was placed on a load-balancing fixture that contained a spherical seat as shown in Figure 3. The specimens were loaded in compression on a $267 \mathrm{kN}(60,000 \mathrm{lbs}$.) Tinius-Olsen electro-mechanical testing machine. Eccentricity of the load was monitored by strain-gages and reduced by adjusting leveling screws on the balancing fixture. Balancing was an iterative process, done in steps starting with a modest load of approximately $5 \mathrm{kN}$ and increasing gradually to the testing load. The testing load was chosen for each specimen under the conditions that the response be within the elastic range and that there be sufficient moire fringes to permit an accurate ply-by-ply analysis. Relatively modest loads were required, and anti-buckling restraints were not necessary.

Interiaminar deformations at the straight edges were obtained using a moiré interferometer that is suitable for the testing machine environment [7]. Fringe patterns were recorded for the longitudinal (in the direction of loading) and the transverse (in the thickness direction) displacements. Strains $\varepsilon_{x}$ (transverse), $\varepsilon_{y}$ (longitudinal), and $\gamma_{x y}$ were calculated and plotted as functions of the ply number.
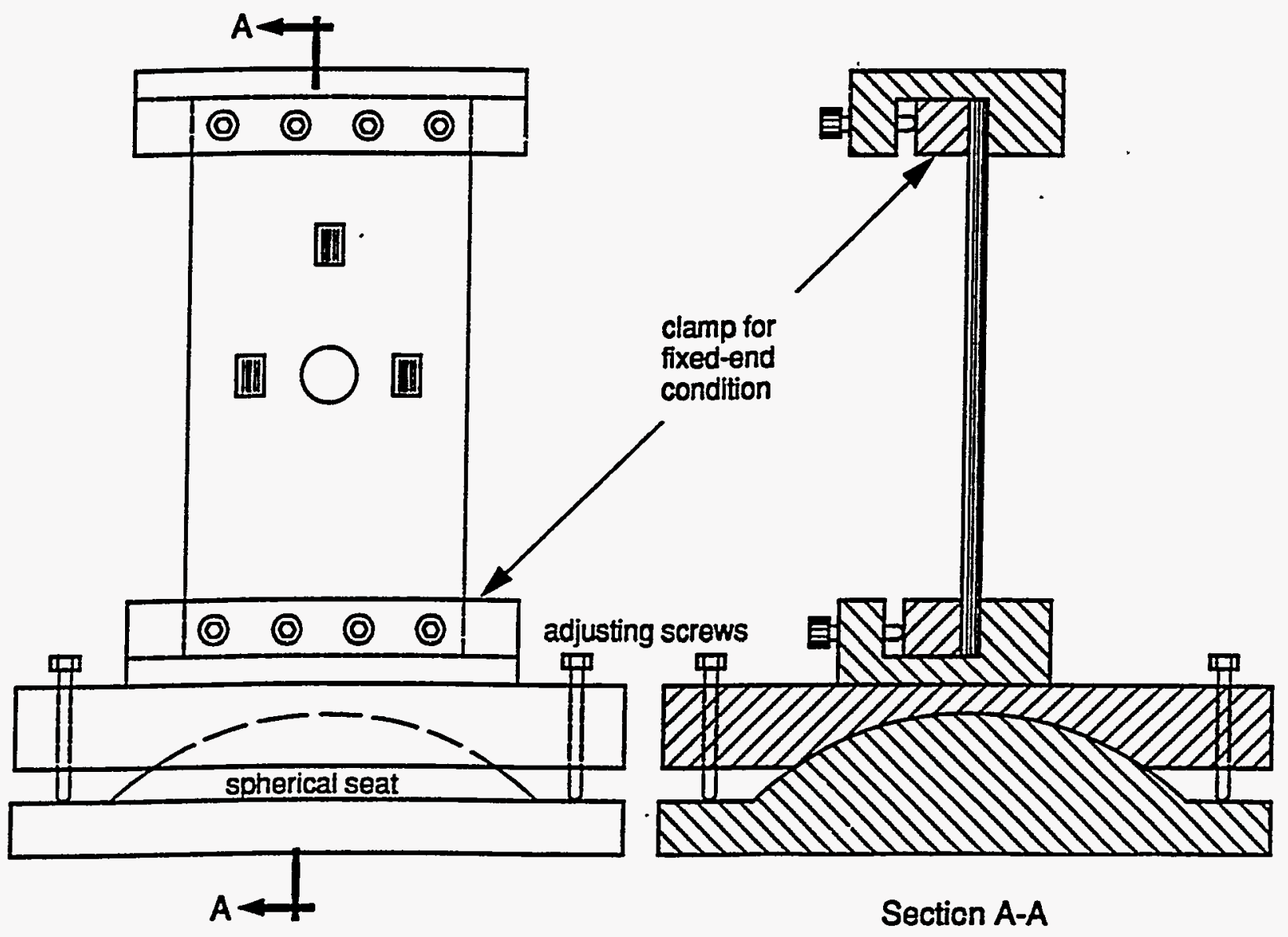

Figure 3 Compression loading fixture with spherical seat and alignment screws. 
Specialized experimental techniques were developed to determine the distributions of the interlaminar strains $\varepsilon_{x}$ (transverse), $\varepsilon_{\theta}$ (tangential), and $\gamma_{x \theta}$ on the cylindrical surface of the hole for specimens $\mathrm{B} 1 \mathrm{H}, \mathrm{B} 2 \mathrm{H}, \mathrm{N} 1$, and $\mathrm{N} 2$. The procedure involves replicating deformed specimen gratings under load for interrogation in a remote interferometer. Strains can be extracted at any angular position $\theta$. The strain distributions reported herein were extracted at angular position $\theta=90^{\circ}$ with respect to the loading axis. Experimental details can be found elsewhere [8].

\section{RESULTS}

\section{Straight Boundary Free Edge}

To serve as a baseline for comparisons, interlaminar strain distributions at the straight free edge were determined. Figure 4 displays the moire fringe patterns obtained for the deformations of specimen B1. The top pattern, Figure 4a, is a contour map of the longitudinal displacement $U_{y}$. The constant fringe gradient in the $y$-direction indicates that each ply

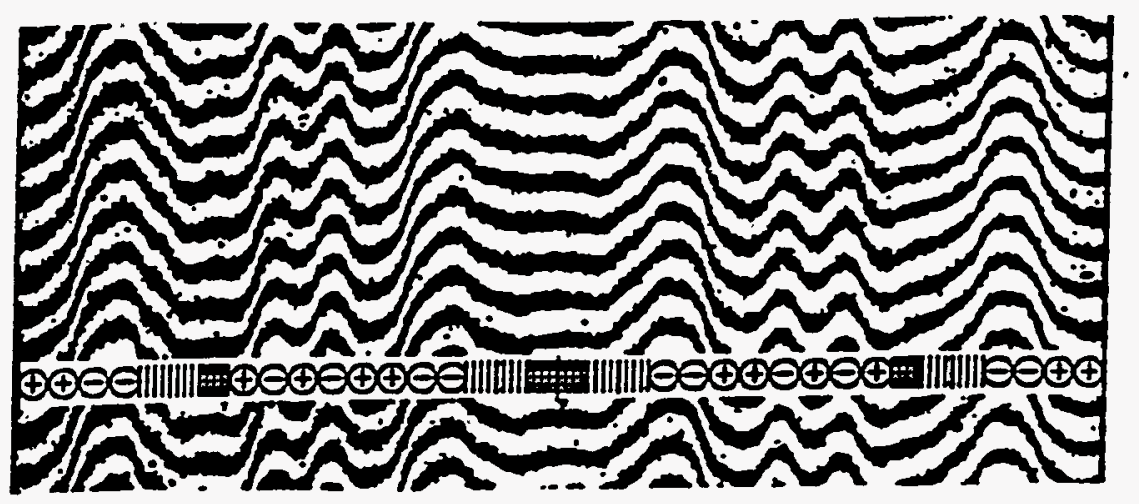

(a)

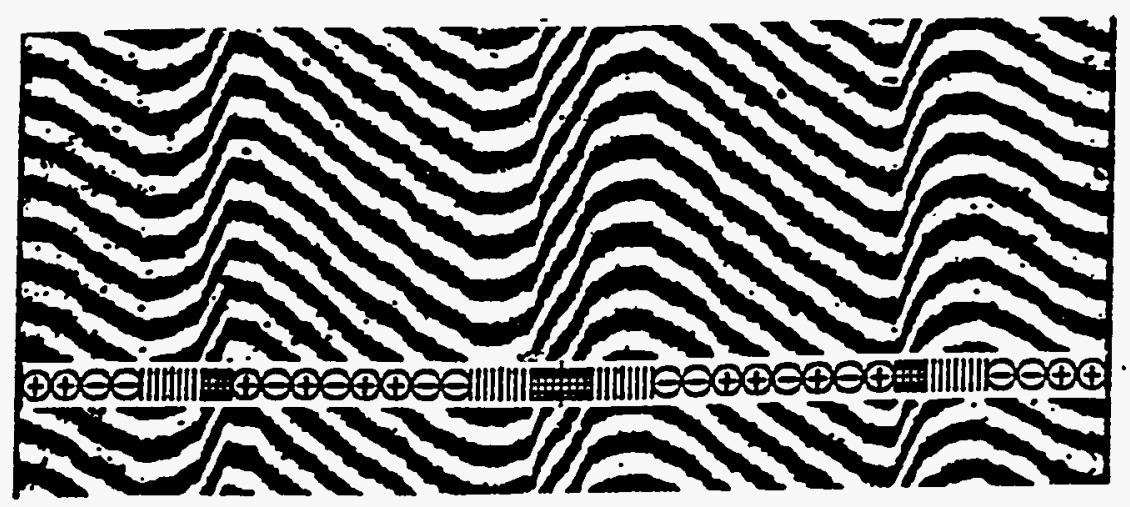

(b)

Figure 4 Representative moire fringe patterns depicting the (a) longitudinal, $U_{y}$, and (b) transverse, $U_{x}$, deformations at the straight boundary for specimen $B 1$. Contour interval $=417 \mu \mathrm{m}$. Load $=71.1 \mathrm{kN}(16000 \mathrm{lbs})$. The overlay defines the ply orientation. 
experiences the same compressive strain $\varepsilon_{y}$. The contour interval is $417 \mu \mathrm{m}$. The bottom pattern, Figure $4 b$, is a contour map of the corresponding transverse displacements $U_{x}$, transformed into a more tractable form for detailed data analysis by the addition of carrier fringes of rotation, i.e., a constant vertical fringe gradient. Ply-by-ply variations of the normal strain $\varepsilon_{\mathrm{x}}$ are manifest as ply-by-ply variations of the slope of the fringes [9]. Figure 5a depicts the though-thickness distribution of the transverse strain $\varepsilon_{x}$ normalized by the magnitude of the axial strain measured from the fringe pattern. Although the overall poisson's effect is positive, the transverse strain exhibits sign reversals and changes rapidly and systematically in concert with the ply orientation. Variations of the interlaminar shear strain, $\gamma_{x y}$, are indicated by the

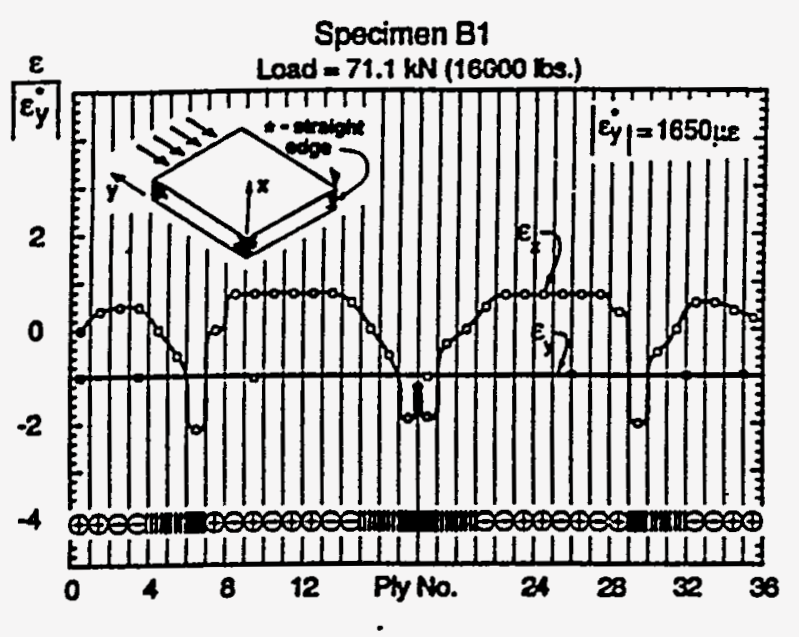

(a)

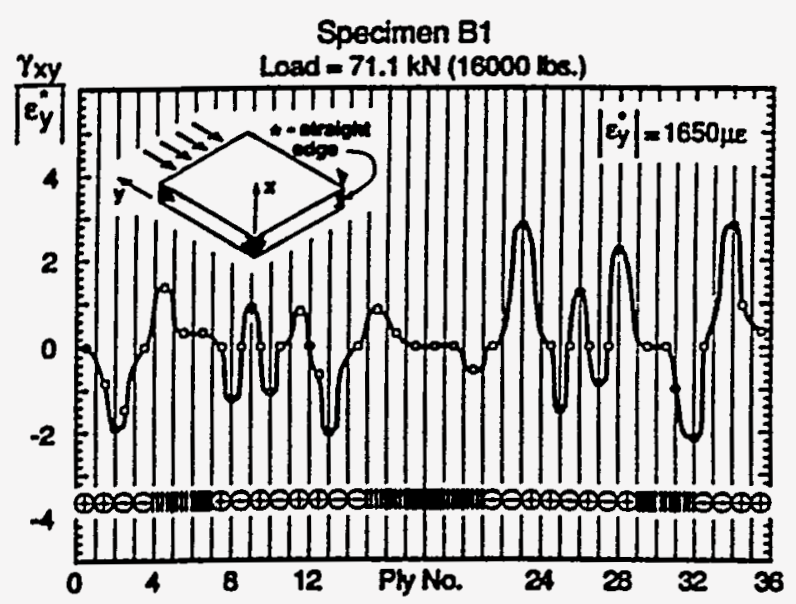

(c)

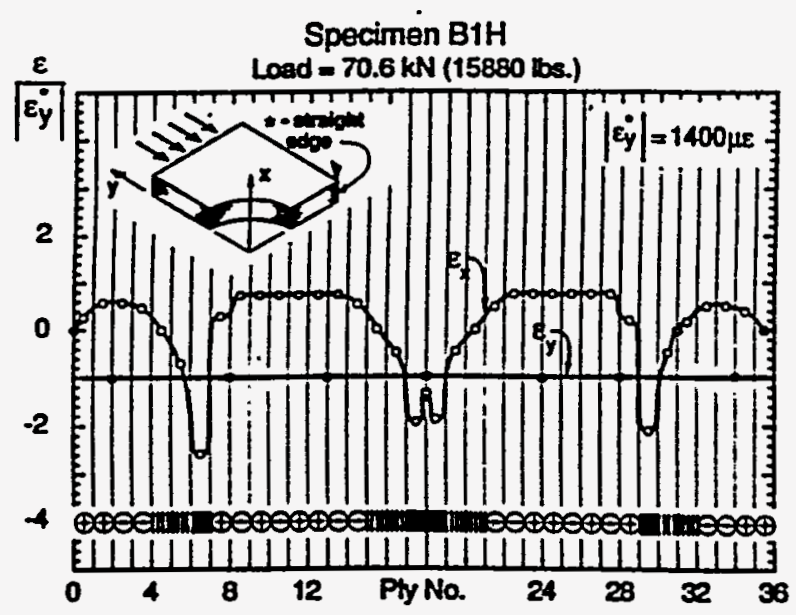

(b)

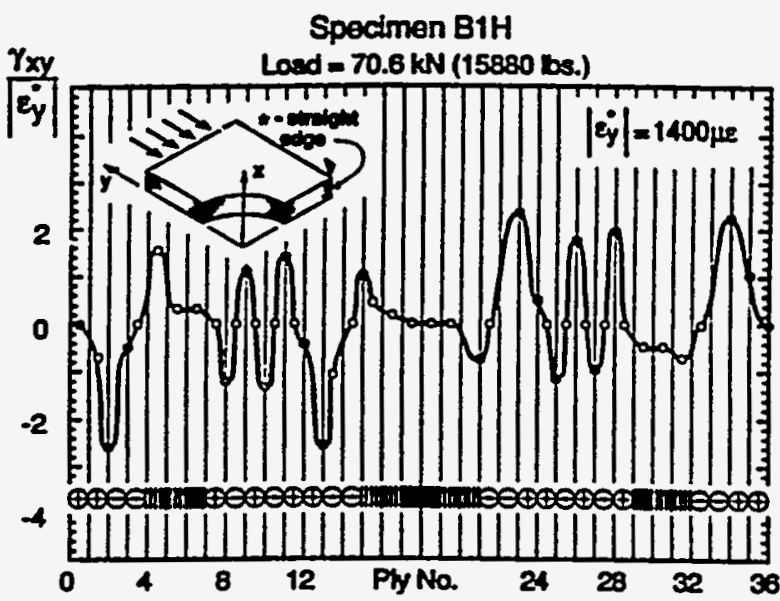

(d)

Figure 5 Interlaminar strain distributions at the straight boundary for specimens with and without holes. 
undulating nature of the $U_{y}$ fringes. Figure $5 b$ represents the corresponding graph of $\gamma_{x y}$ and indicates that large values occur at interfaces between $+45^{\circ}$ and $-45^{\circ}$ layers. Ideally, the curve should be antisymmetical about the center plane. The variation or scatter in the magnitudes of the peak values is attributed to material variability, where nominally equal plies exhibit slightly different responses. Figure 5 shows that the strains are essentially the same along the straight boundaries for specimens with and without holes. Accordingly, the strains at the straight boundary are used as normalizing factors and represents both cases.

\section{Tangential Strains in Hole at $\theta=90^{\circ}$}

Fringe patterns for the $U_{x}$ and $U_{\theta}$ displacements were obtained form the hole surface. A representative fringe pattern for the $90^{\circ}$ location is shown in Figure 6 for specimen N1. Tangential strains, $\varepsilon_{\theta}$, were obtained at the horizontal centerline, $\theta=90^{\circ}$. Figure 7 shows that the distribution of $\varepsilon_{\theta}$ at the hole differs dramatically from the corresponding strains at the straight boundary, both in magnitude and distribution. At the straight edge, $\varepsilon_{y}$, is constant throughout the thickness, whereas at the hole, $\varepsilon_{\theta}$ is amplified on a ply-by-ply basis. Amplification factors can be quite large, reaching 7.5 for specimen N2.

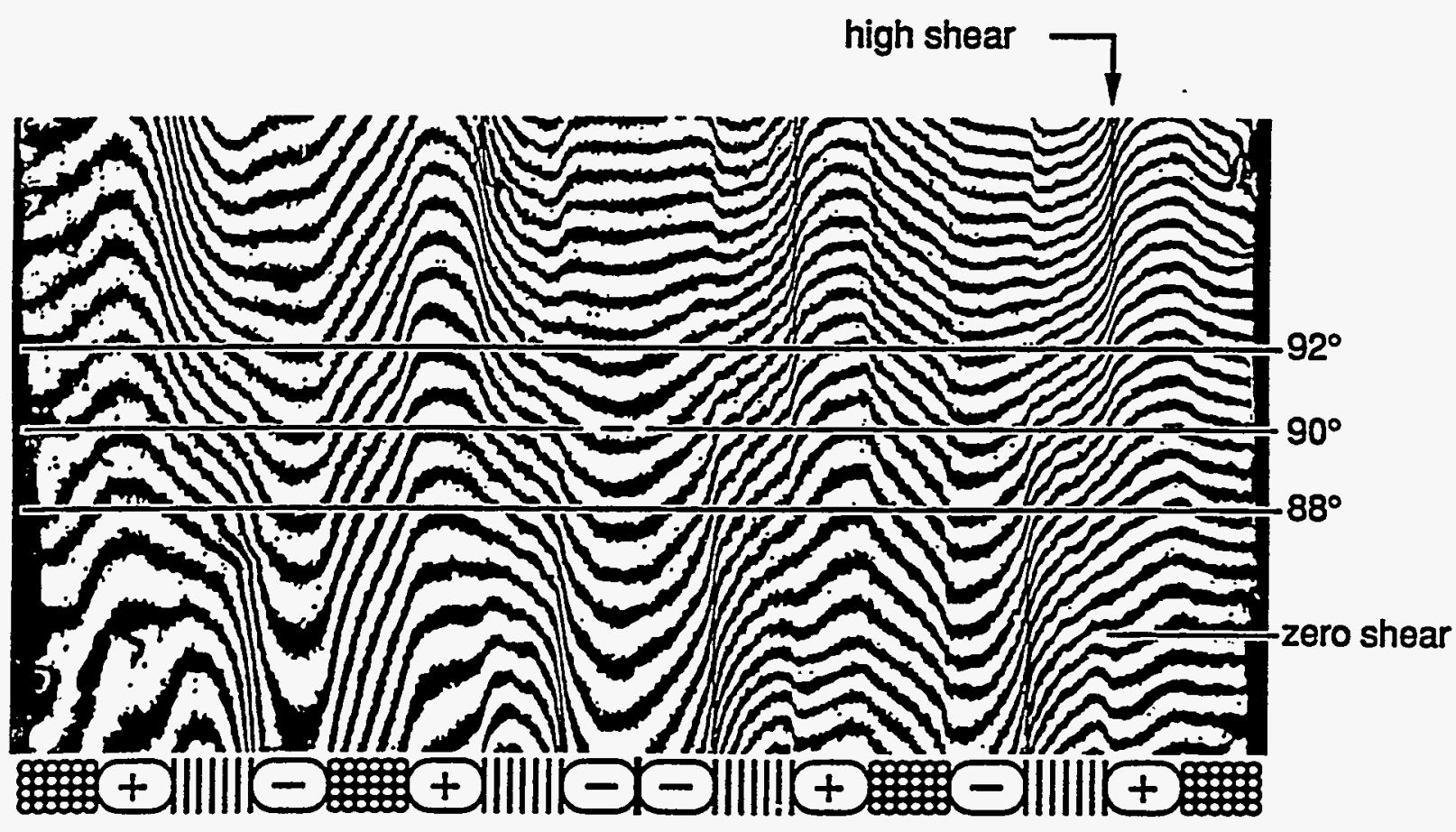

Figure 6 Representative moire fringe pattern depicting the tangential deformation, $U_{\theta}$, on the hole boundary for specimen N1. Only the region near the horizontal centerline is shown. 


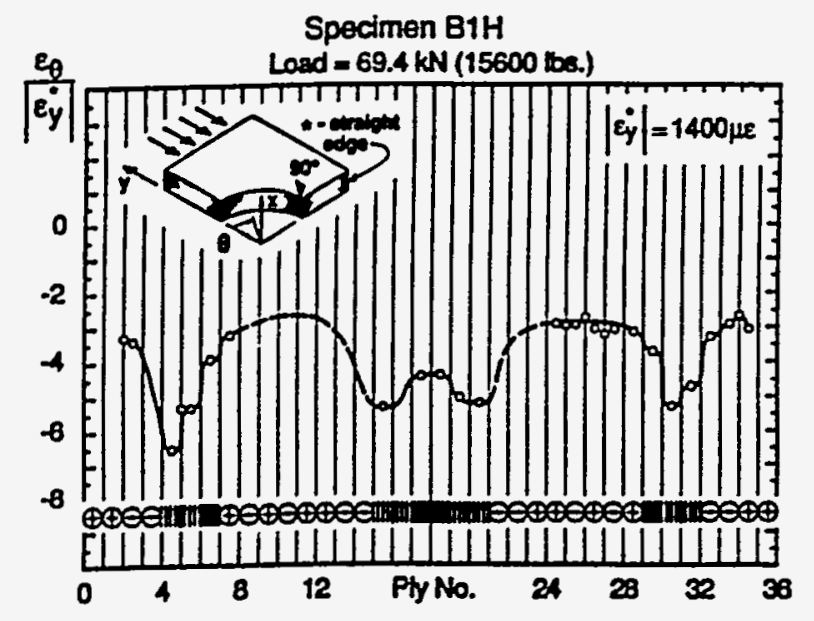

(a)

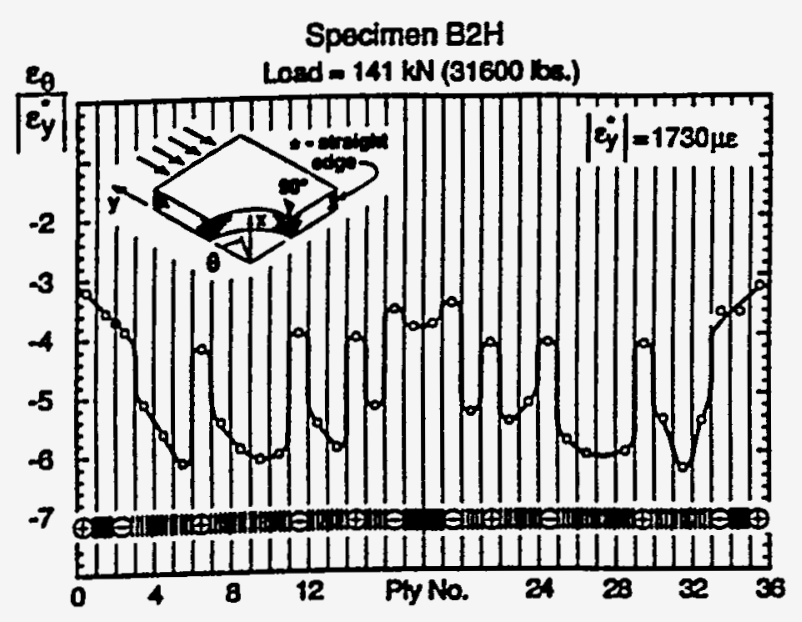

(c)

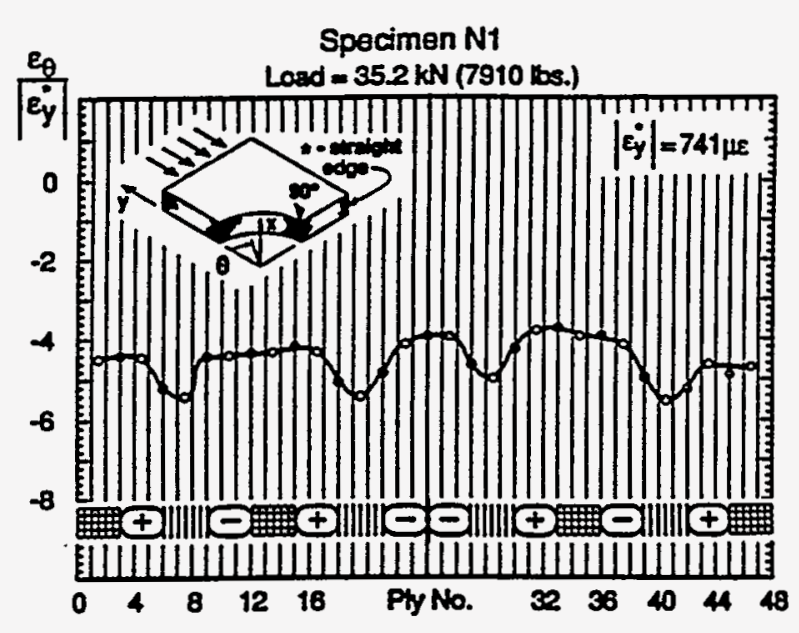

(b)

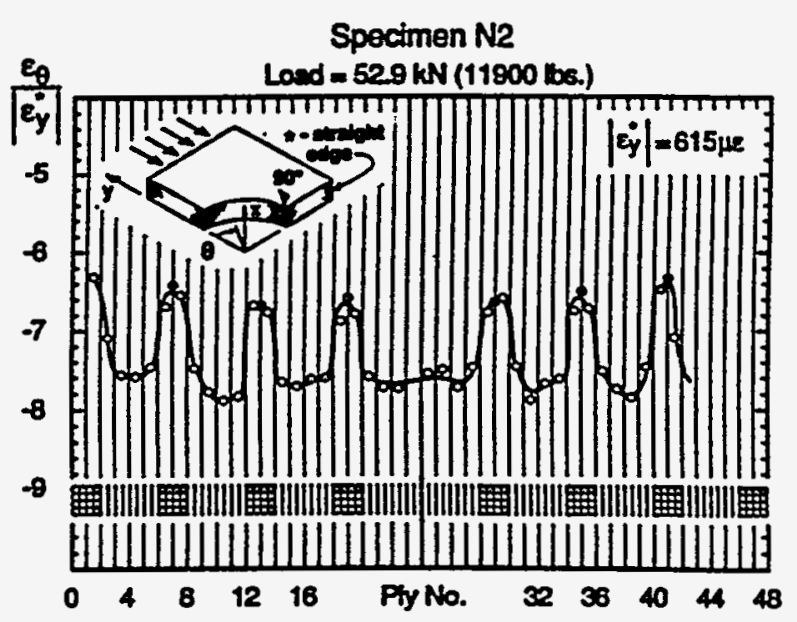

(d)

Figure 7 Tangential strain distributions at the horizontal centerline for the hole boundary. The strains are amplified on a ply-by-ply basis.

\section{Transverse Strains in Hole at $\theta=90^{\circ}$}

Figure 8a shows that the transverse strain, $\varepsilon_{x}$, at the $90^{\circ}$ location exhibits a very similar trend to that of the corresponding straight boundary free-edge distributions shown in Figure 5. Significant differences are evident, however. For example, whereas the magnitudes of the tensile strains that occur in the $45^{\circ}$ plies are nearly doubled, the magnitudes of the compressive strains in the $90^{\circ}$ plies are approximately of equal value. This indicates that the response at the hole is modulated on a ply-by-ply basis. The remaining plots in Figure 8 illustrate that the transverse strains have markedly different distributions at the hole and straight boundaries. 


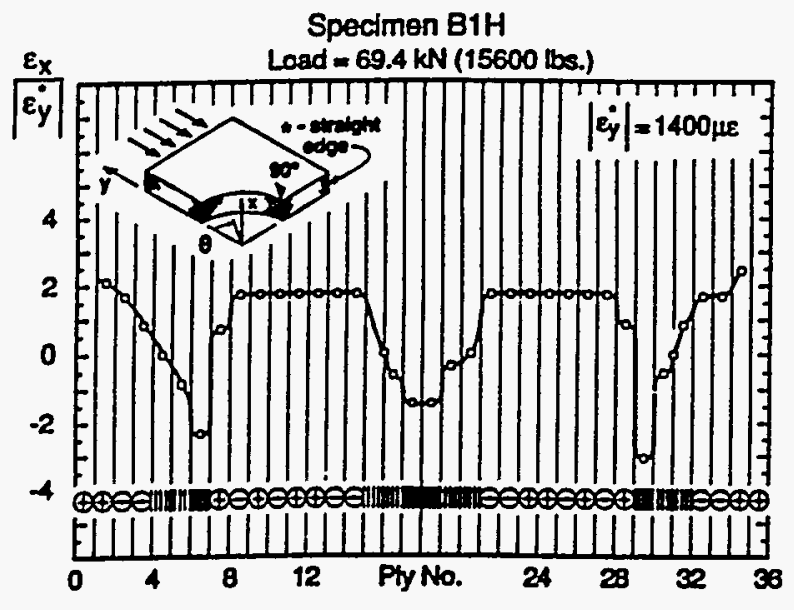

(a)

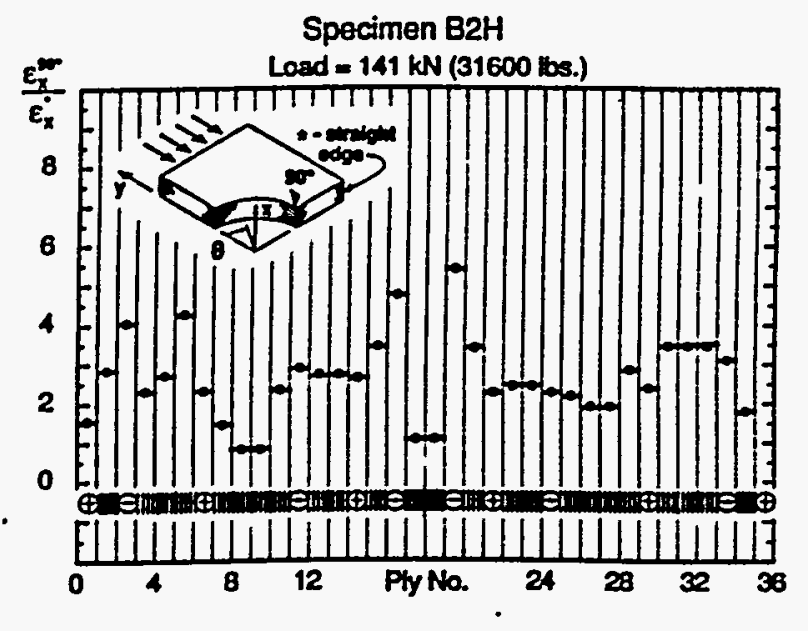

(c)

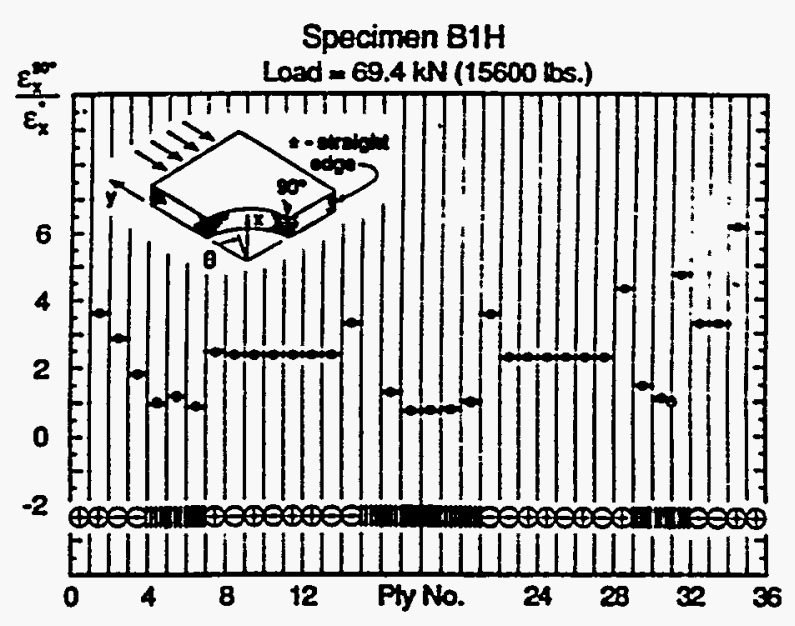

(b)

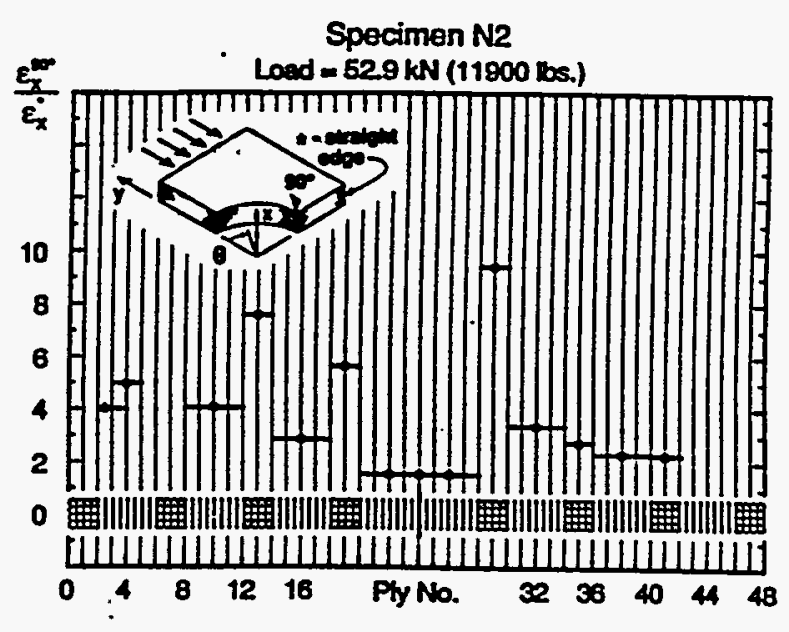

(d)

Figure 8 Transverse strain distributions at the horizontal centerline for the hole boundary. The strains have markedly different distributions at the hole and straight boundaries.

\section{SUMMARY}

Free-edge effects in laminated composite materials were studied experimentally using high-sensitivity moire interferomety. Interlaminar deformations were measured on a ply-by-ply basis for straight and curved boundaries in laminated composite panels. Interlaminar strain distributions at the straight boundary were found to be essentially the same for specimens with and without holes. Accordingly, the strains at the straight boundary were used as normalizing factors for the response at the hole. The measurements on the curved boundary of the holes appear to be unique, representing the first experimental analyses on a ply-by-ply basis. Interiaminar strains were determined with high fidelity and plotted versus the ply number at the horizontal centerline. Results indicate that the tangential strains at the hole are dramatically 
different from the corresponding strains at the straight boundary, both in magnitude and distribution. The tangential strains are not proportional, on a ply-by-ply basis, to those at the straight boundary, but are amplified by factors that appear to be a function of the ply orientation and stacking sequence for each ply. Transverse strains experience similar amplifications at the hole boundary. The results are reasonable systematic, but exceptions are noted and attributed to variations of properties of nominally equivalent plies.

\section{ACKNOWLEDGEMENTS}

The experimental work described herein was conducted at the Photomechanics Laboratory at the Virginia Polytechnic Institute and State University. The author wishes to express his sincere appreciation to professor Dan Post for his encouragement and many helpful suggestions during the course of this work. The research was supported by the Office of Naval Research (ONR) under grant N00014-90-J1688, the National Center for Composite Materials Research (Urbana, Illinois) under University Research Initiation grant from ONR N0014-86-K0799, and the Boeing Commercial Airplane Group under contract TZ-6899000A57N. Specimens N1 and N2 were supplied by Dr. Mark Shuart of NASA-Langley. Specimens B1, B1H, B2, and B2H were supplied by Dave Cooper of Boeing. This support is greatly appreciated and warmly acknowledged.

\section{REFERENCES}

[1] Kassapoglou, C. and Lagace, P. A. "An Effecient Method for the Calculation of Interlaminar Stresses in Laminated Composites," Journal of Applied Mechanics, Vol. 53, pp. 744-750, December 1986.

[2] Pipes, R. B. and Pagano, N. J. "Interlaminar Stresses in Composite Laminates Under Uniform Axial Extension," Journal of Composite Materials, Vol. 4, pp. 538-548, October 1970.

[3] Wang, A. S. D. and Crossman, F. W. "Some New Results on Edge Effects in Symmetric Composite Laminates," Journal of Composite Materials, Vol. 11, pp. 92-106, January 1977.

[4] Wang, S. S. and Choi, I. "Boundary-Layer Effects in Composite Laminates: Part 2 Free-Edge Stress Solutions and Basic Characteristics," Journal of Applied Mechanics, Vol. 49, pp. 549-560, 1982.

[5] Post, D. "Moiré Interferometry," Chapter 7, Handbook of Experimental Mechanics, A. S. Kobayashi, Ed., Prentice-Hall, Englewood Cliffs, NJ, 1987.

[6] Post, D. "Moiré Interferometry for Composites," Section IV A-2, Manual on Experimental Methods for Mechanical Testing of Composites, R. L. Pendleton and M. E. Tuttle, Eds., Society for Experimental Mechanics, Inc., Bethel, CT, 1989.

[7] Guo, Y. and Ifju, P., "Practical Moiré Interfeometry System for Testing Machine Applications," Experimental Techniques, (15)1, pp. 29-31, 1991.

[8] Boeman, R. G., "Interlaminar Deformations on the Cylindrical Surface of a Hole in Laminated Composites: An Experimental Study," Center for Composite Materials and Structures Report, Virginia Polytechnic Institute and State University, CCMS-91-07, 1991.

[9] Guo, Y., Post, D., Czarnek, R. "The Magic of Carrier Patterns in Moiré Interferometry," Experimental Mechanics, Vol. 29, No. 2, pp. 169-173, June 1989. 